\title{
MEMPREDIKSI NILAI KEKASARAN PERMUKAAN DENGAN BESARNYA GETARAN AMPLITUDO PADA GERAK CROSS FEED PROSES GERINDA DATAR DENGAN MATERIAL HARDENED TOOL STEEL SKD11
}

\author{
Chairul Anam dan Dian Ridlo Pamuji \\ Staf Pengajar Prodi Teknik Mesin Politeknik Negeri Banyuwangi \\ e-mail: anam_syifa@yahoo.com \\ Naskah diterima: 14 Juni 2017 ; Naskah disetujui: 26 Juni 2017
}

\begin{abstract}
ABSTRAK
Proses gerinda merupakan bagian akhir dalam proses pemesinan, karena membutuhkan ketelitian dimensi tinggi dan tingkat kekasaran permukaan rendah. Hubungan antara level getaran (g.rms) dan kekasaran permukaan ( $\mu \mathrm{m})$ digambarkan secara linier dengan determinasi sebesar 99.92\%. Hasil penelitian menunjukan bahwa semakin besar kecepatan cross feed maka amplitudo dan kekasaran permukaan akan semakin naik sehingga kontribusi yang diberikan dapat memprediksi kekasaran permukaan dengan mengukur level getaran selama proses penggerindaan, tanpa harus melakukan pengukuran kekasaran permukaan.
\end{abstract}

Kata Kunci: Gerinda datar, cross feed, getaran, kekasaran permukaan.

\section{PENDAHULUAN}

Penggunaan mesin gerinda merupakan bagian akhir dari berbagai proses pemesinan [1][2]. Terdapat dua proses penggerindaan, yaitu proses pengasaran dan proses penghalusan. Pada proses pengasaran (roughing), getaran dapat merusak dan memperpendek umur pahat/ mesin. Sedangkan dalam proses penghalusan (finishing) akan mengurangi ketelitian dimensi, bentuk serta kehalusan permukaan benda kerja . Oleh karena itu, perlu dihindari terjadinya getaran. Getaran yang terjadi pada proses pemesinan adalah sangat berbahaya dan tidak diinginkan . Hal ini terjadi karena adanya sumber penggetar/ eksitasi yang merambat melalui keseluruhan komponen/ bagian mesin yang bersangkutan [3][4][5]. Kedalaman potong dan kecepatan makan yang semakin besar akan meningkatkan amplitudo, kekasaran permukaan dan pertumbuhan chatter [6][7].

\section{TINJAUAN PUSTAKA}

Proses gerinda adalah salah satu tipe dari abrasive machining yang digunakan untuk proses finishing. Proses ini merupakan proses pelepasan material dengan menggunakan pahat yang berupa batu gerinda berbentuk piringan (grinding wheel/disk), yang dibuat dari campuran serbuk abrasif dan bahan pengikat dengan komposisi dan struktur tertentu. Dengan menggunakan proses gerinda maka kekasaran permukaan produk yang rendah dan toleransi geometrik yang sempit dapat dicapai dengan cara yang mudah, serta dapat digunakan untuk menghaluskan dan meratakan benda kerja yang telah dikeraskan.

Getaran dalam bidang dinamika mesin perkakas dapat dibagi menjadi tiga jenis, getaran bebas (free vibration), getaran paksa (forced vibration), dan getaran terekstitasi diri (self-excited vibration) (Koenigsberger dan Tlusty (1970) Boothroyd dan Knight, 1989), dimana self-excited vibration juga disebut chatter.

Pada saat proses pemotongan sedang berlangsung maka getaran harus dihindari karena getaran bersifat merugikan, diantaranya menurunkan kualitas permukaan, mengurangi tingkat kepresisian dimensi benda kerja, menyebabkan pahat mudah aus bahkan patah pahat dini, serta bisa mengakibatkan kerusakan mesin atau poros. Banyak penelitian yang berkaitan tentang kasus getaran dan kekasaran permukaan benda kerja dengan parameter berbeda-beda diantaranya adalah sebagai berikut [7].

Leonesio dkk. (2012), melakukan penelitian tentang simulasi dinamik sebagai model dari gerinda datar terhadap waktu, dimana kualitas benda kerja pada proses gerinda dipengaruhi oleh keadaan statik dan dinamik pada suatu sistem mekanik. Kelenturan dinamik (dynamic compliance) menyebabkan getaran 
yang membuat kualitas permukaan benda kerja menurun.

Penelitian ini menggunakan material baja karbon rendah (Fe510-EN 10027) dengan dimensi 260 $\mathrm{mm} \times 210 \mathrm{~mm}$ × $40 \mathrm{~mm}$. dengan tipe batu gerinda 7A36IBJ15, berdimensi 400 x 57. Dengan memvariasikan kedalaman potong, kecepatan makan dan putaran roda gerinda.

Inasaki dkk. (2001), melakukan penelitian tentang chatter pada material S55C dengan menggunakan batu gerinda tipe WA60JmV. Hasilnya adalah bahwa chatter tumbuh dengan sangat cepat apabila kondisi kedalaman potong, lebar penggerindaan dan kecepatan gerinda yang besar, serta kecepatan benda kerja yang rendah. Kemudian dengan manaikkan kekakuan (stiffness) dan peredaman (damping) pada sistem makanik dapat menurunkan laju pertumbuhan/ terbentuknya chatter.

\section{METODE PENELITIAN}

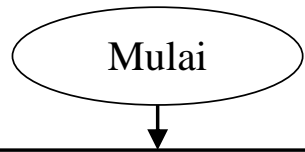

Rancangan penelitian

Material: SKD 11 yang mengalami perlakuan panas (58 HRC)

* Variabel Proses:

- Tipe batu gerinda (A80LV dan A46QV)

- Kedalaman potong $(0,01 ; 0,02 ; 0,03)(\mathrm{mm})$

- Cross feed $(5,3 ; 6,8 ; 8,4 ; 9,9 ; 11,7)$ (mm/langkah)

Variabel Respon:

- Kekasaran permukaan $\left(\mathrm{R}_{\mathrm{a}}, \mu \mathrm{m}\right)$

- Getaran ( g.rms )

* Variable konstan

$\mathrm{n}$ putaran gerinda $=3000 \mathrm{rpm}$

Dimensi batu gerinda $=200 \mathrm{~mm}$ x $32 \mathrm{~mm}$ x 25

Persiapan penelitian:

- Mesin gerinda datar merk Krisbow KGS818AH

- Batu gerinda tipe (A80LV dan A46QV)

- Peralatan uji getaran

- Surface roughness tester

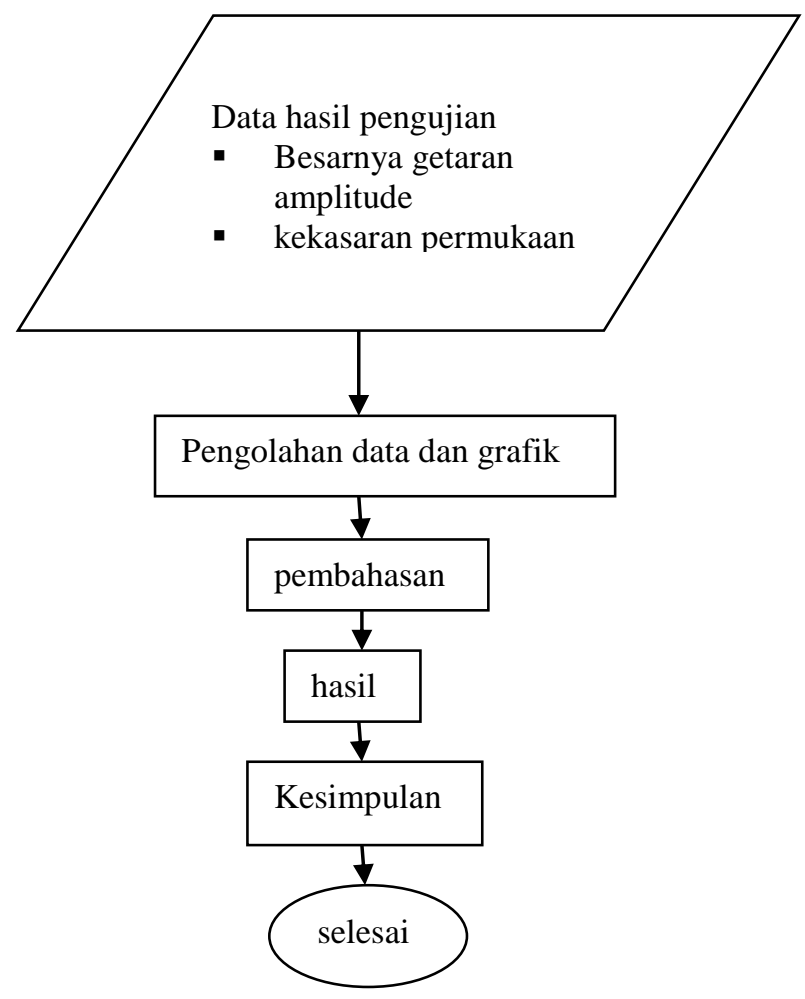

Gambar 1 Diagram Alir Penelitian

\section{Alat Penelitian}

Adapun alat yang digunakan sebagai berikut:

1. Mesin Gerinda datar KGS818AH,

2. Accelerometer,

3. Power Supply,

4. ADC (analog to digital converter) picotech

5. Komputer.

6. Surface Roughness Tester

Untuk Skema pemasangan uji pemotongan sebagai berikut:

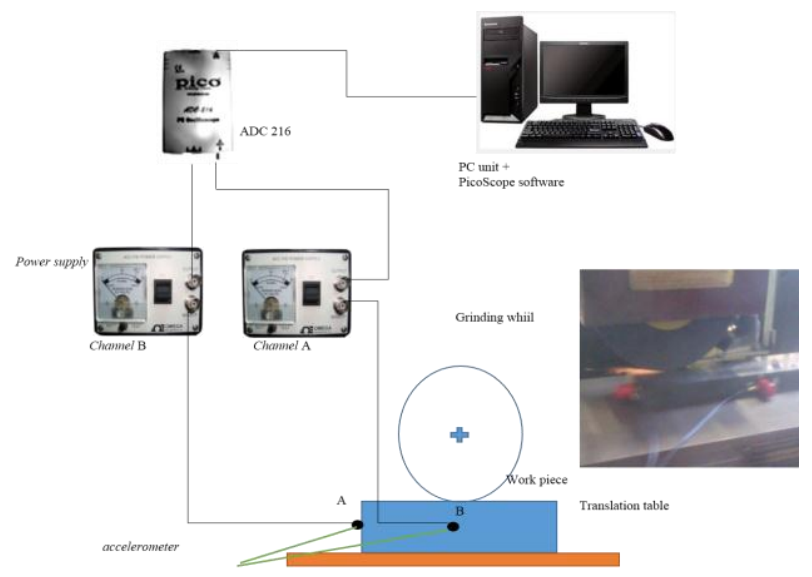

Gambar 2 Skema pemasangan uji pemotongan 


\section{Bahan Penelitian}

Mesin gerinda permukaan memiliki spesifikasi sebagai berikut:

1. Jenis Mesin : Surface Grinding Type KGS818AHD

2. Dimensi meja kerja $200 \times 500 \mathrm{~mm}$

3. Kecepatan putaran $3000 \mathrm{rpm}$

4. Dimensi batu gerinda $200 \times 25 \times 32 \mathrm{~mm}$

Material yang digunakan adalah baja perkakas SKD-11 yang memiliki kekerasan sebesar 58 HRC dengan dimensi $300 \mathrm{~mm} \times 60 \mathrm{~mm} \times 20 \mathrm{~mm}$, material benda kerja yang akan digunakan di tunjukan pada Gambar 3 sebagai berikut:

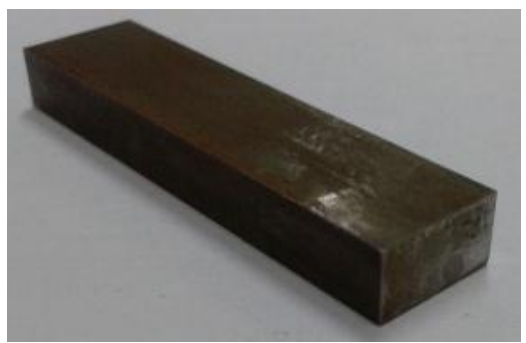

Gambar 3 Benda kerja SKD-11

Sedangkan komposisi kimia dan sifat mekanik dari SKD-11 dapat dilihat pada Tabel 1 sebagai berikut:

Tabel 1 Komposisi kimia SKD 11

\begin{tabular}{|c|c|}
\hline Jenis Kimia & Persentase (\%) \\
\hline Carbon $(\mathrm{C})$ & 1.55 \\
\hline Silicon $(\mathrm{Si})$ & 0.25 \\
\hline Manganese $(\mathrm{Mn})$ & 0.30 \\
\hline Phosphorus & 0.024 \\
\hline Chromium $(\mathrm{Cr})$ & 11.50 \\
\hline Nickel $(\mathrm{N})$ & 0 \\
\hline Molybdenum $(\mathrm{Mo})$ & 0.70 \\
\hline Vanadium $(\mathrm{V})$ & 1.00 \\
\hline Copper $(\mathrm{Co})$ & 0 \\
\hline
\end{tabular}

Sumber: Paragon catalog specialty metals and services

Batu gerinda aluminium oxide Dimensi batu gerinda yang digunakan pada penelitian ini adalah $200 \times 25 \times 32$ $(\mathrm{mm})$ dengan dua ukuran butiran (grain size/ grit) 46.

Adapun gambar batu gerinda seperti pada Gambar 4 .

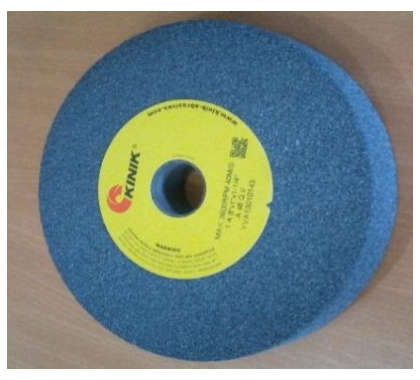

Gambar 4 Batu gerinda aluminium oxide

\section{Parameter Penelitian}

Variabel proses adalah kecepatan cross feed yang di tentukan: (5.3, 6.8, 8.4, 9.9 dan 11.7) (mm/langkah). Variabel konstan adalah putaran spindel $3000 \mathrm{rpm}$ dan longitudinal feed $50 \mathrm{~mm} / \mathrm{s}$. Kedalaman potong $0.01 \mathrm{~mm}$. Variabel respon adalah amplitudo getaran (g.rms)

\section{Prosedur penelitian}

A. Tahap persiapan:

1. Siapkan mesin surface grinding dan benda kerja yang akan digunakan untuk uji pemotongan.

2. Melakukan dressing pada batu gerinda, sebelum dilakukan penelitianagar kondisi permukaan batu gerinda rata.

3. Cekam benda kerja pada mesin surface grinding dengan sistem pencekaman meja magnet sebelum dilakukan uji pemotongan .

4. Melakukakn setting titik nol benda kerja terhadap batu gerinda.

5. Melakukan setting parameter proses, seperti kedalaman potong dan cross feed sebagai variabel proses dan kecepatan makan sebagai variabel konstan

6. Memasang dan merakit alat uji getaran, seperti PC, ADC picoscope, kabel, accelerometer pada benda kerja searah sumbu x (channel $A$ ) dan searah sumbu $\mathrm{z}$ (channel B), dan power supply seperti Gambar 2.

Kemudian dilakukan pengujian awal terhadap kerja accelerometer dengan cara mengetuk benda kerja, sehingga timbul eksitasi getaran pada layar komputer.

7. Lakukan pengaturan pada tampilan PicoScope

B. Tahap pemotongan:

1. Klik tombol start/running pada display PicoScope sebagai tanda akan dimulainya pengambilan data.

2. Nyalakan mesin surface grinding, putaran spindel utama (batu gerinda) bergerak searah putaran jarum jam.

3. Melakukan pemotongan dengan cara benda kerja bergerak translasi dan batu gerinda berputar searah jarum jam bergerak turun sesuai dengan kedalaman potong yang ditetapkan, hingga bersentuhan dan terjadi pemotongan. Pemotongan dilakukan hingga terjadi chatter yang ditandai dengan suara bising yang berlebihan dan meningkatnya kekasaran 
permukaan hasil pemotongan. Getaran yang terjadi akan terbaca oleh accelerometer yang terpasang pada material benda kerja. Signal getaran yang masih berbentuk analog selanjutnya dikirim ke $A D C$ melalui constant curret power supply untuk diubah menjadi signal digital. Selanjutnya signal digital dikirim ke komputer dengan bantuan perangkat lunak PicoScope sebagai spectrum analyser, signal tersebut diubah menjadi spektrum gelombang yang dapat dibaca dilayar monitor. Kemudian spektrum tersebut dapat disimpan ke dalam bentuk file lain (convert), misalnya dalam bentuk text file (.txt), sehingga data tersebut bisa diolah menggunakan perangkat lunak MathCad untuk mendapatkan nilai respon frekuensi dan amplitudonya.

\section{HASIL DAN PEMBAHASAN}

Hasil analisis getaran menunjukkan bahwa dengan meningkatnya kecepatan cross feed nilai amplitudo dan kekasaran permukaan selalu cenderung naik seperti di tunjukan pada Gambar 5 di bawah ini.

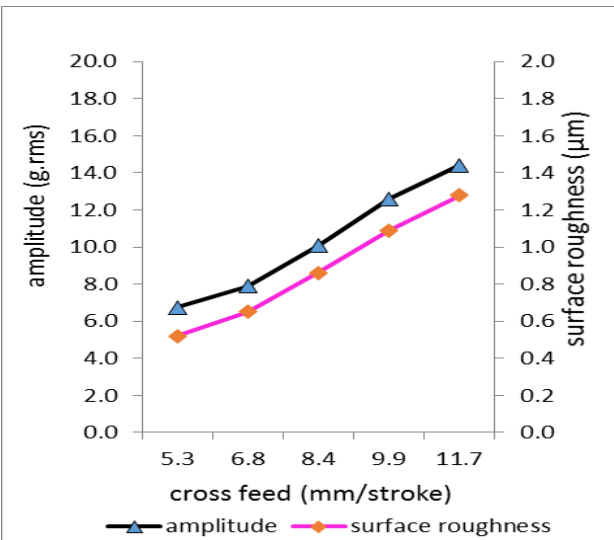

Gambar 5. Hubungan antara amplitudo, kecepatan cross feed, dan kekasaran permukaan untuk kedalaman 0.01 $\mathrm{mm}$.

Pada Gambar 5 menunjukkan bahwa pola kenaikan antara amplitudo dan kekasaran permukaan berbanding lurus seiring dengan meningkatnya kecepatan cross feed sebagaimana ditunjukan pada Tabel 2 sebagai berikut :

Tabel 2. Pola kanaikan nilai amplitudo dan kekasaran permukaan untuk kedalaman potong $0.01 \mathrm{~mm}$

\begin{tabular}{|l|l|l|l|l|l|}
\hline \multirow{2}{*}{ Keterangan } & \multicolumn{5}{|c|}{ Kecepatan cross feed (mm/langkah) } \\
\cline { 2 - 6 } & 5.3 & 6.8 & 8.4 & 9.9 & 11.7 \\
\hline $\begin{array}{l}\text { Amplitude } \\
\text { (g.rms) }\end{array}$ & 6.73 & 7.89 & 10.07 & 12.61 & 14.42 \\
\hline $\begin{array}{l}\text { Kekasaran } \\
\text { permukaan } \\
(\mu \mathrm{m})\end{array}$ & 0.52 & 0.65 & 0.86 & 1.09 & 1.28 \\
\hline
\end{tabular}

Dari Tabel 2 hubungan linier antara amplitudo dengan kekasaran permukaan bisa di dapatkan grafik sebagai berikut :

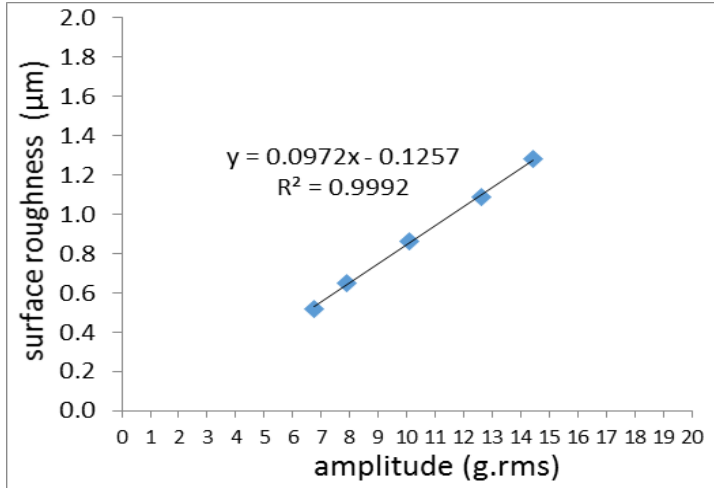

Gambar 6. Hubungan antara amplitudo dengan kekasaran permukaan untuk kedalaman $0.01 \mathrm{~mm}$.

Pada Gambar 6 menunjukan bahwa besar nilai amplitudo akan semakin naik seiring dengan besar nilai kekasaran permukaan. Setiap perubahan parameter cross feed akan mempengaruhi besarnya nilai amplitudo dan kekasaran permukaan.

Sehingga dari Gambar 6 didapatkan persamaan garis linier, dimana amplitudo sebagai predictor terhadap kekasaran permukaan. Adapun persamaannya sebagai berikut :

$Y=0.0972 X-0.1257$

$R^{2}=0.9992$

Berdasarkan persamaan tersebut, tingkat amplitudo bisa memprediksi tingkat kekasaran permukaan tanpa harus mengukur nilai kakasaranya dengan determinasi sebesar $99,92 \%$.

\section{KESIMPULAN}

Hasil penelitian ini adalah kekasaran permukaan proporsional langsung dengan amplitudo getaran. Kecenderungan linearitas dapat dirumuskan dan digunakan sebagai prediksi nilai kekasaran permukaan. Itu hanya menggunakan pengukuran sinyal getaran untuk memprediksi kekasaran permukaan benda kerja pada proses penggerindaan.

\section{DAFTAR PUSTAKA}

[1] Rochim T. 1993. Teori dan Teknologi Proses Pemesinan. Institut Teknologi Bandung.

[2] Schey J. Introduction to Manufacturing Processes. New York: McGraw Hill. 2000.

[3] Mobley R.K. 1999. Vibration Fundamentals. USA : Butterworth-Heinemann.

[4] Koenigsberger F, Tlusty J. 1970. Machine Tool Structures. Volume 1. New York: Pergamon Press.. 
[5] Zaveri K. 1984. Modal Analysis of Large Structures - Multiple Exciter System. 1st edition. Bruel \& Kjaer.

[6] Li H, Shin YC. 2006. Wheel Regenerative Chatter of Surface Grinding. Journal of Manufacturing Science and Engineering. Hal 128: 393-403.

[7] Artika, K.D., dan Suhardjono. 2015. Studi Eksperimental Pengaruh Longitudinal Feed Pada Proses Gerinda Datar Terhadap Getaran Dan Kekasaran Permukaan Pada Material Hardened Tool Steel OCR12VM, SNTM 2015 "Unjani Bandung, 2 Desember 2015. 